\title{
Chemical composition and biological activity of extracts from fruiting bodies and mycelial cultures of Fomitopsis betulina
}

\author{
Katarzyna Sułkowska-Ziaja ${ }^{1}$ Agnieszka Szewczyk ${ }^{1}$ - Agnieszka Galanty ${ }^{2}$ · Joanna Gdula-Argasińska ${ }^{3}$. \\ Bożena Muszyńska ${ }^{1}$
}

Received: 25 May 2018 / Accepted: 4 October 2018 / Published online: 13 October 2018

(c) The Author(s) 2018

\begin{abstract}
Fomitopsis betulina (Bull.) B.K. Cui, M.L. Han \& Y.C. Dai has been used for medicinal purposes for over 5000 years. Numerous studies have confirmed the biological activity of compounds found in this species. The purpose of this study was a comparative analysis of selected groups of metabolites in the extracts from fruiting bodies and mycelial cultures. Phenolic acids (syringic, gallic, $p$-hydroxybenzoic, 3,4-dihydrophenylacetic), indole compounds (L-tryptophan, 5-hydroxy-L-tryptophan, 5-methyltryptamine), sterols (ergosterol, ergosterol peroxide, hexestrol, cholecalciferol), and triterpenes (betulinic acid, betulin) were determined quantitatively by high performance liquid chromatography with UV-Vis/DAD detection, while fatty acids were assessed with the gas chromatography method. Cytotoxic activity against selected human cancer cell lines was determined using the lactate dehydrogenase test. Anti-inflammatory activity was evaluated on lipopolysaccharide activated A549 cells. Those extracts with anti-inflammatory activity were evaluated for their inhibition of pro-inflammatory enzymes. The mycelium extract exhibited significant cytotoxic activity against prostate cancer cells, while the fruiting body extract indicated a moderate effect on the viability of melanoma and prostate cancer. Incubation of lung epithelial cells with biomass extract significantly decreased cyclooxygenase-2 levels compared to LPS activated A549 cells. This paper is the first report of a comparative quantitative analysis of the metabolites in mycelial cultures and fruiting bodies. In addition, a novel element of this study is its comparison of the cytotoxic and anti-inflammatory activity of the obtained extracts. The results of comparing the composition and activity of mycelium and fruiting bodies shows that the cultures could be proposed as a potential biotechnological source for selected biologically active compounds.
\end{abstract}

Keywords Fomitopsis betulina $\cdot$ Mycelial culture $\cdot$ Cytotoxic activity $\cdot$ Anti-inflammatory activity $\cdot$ Betulin $\cdot$ Betulinic acid

\section{Introduction}

Fomitopsis betulina (Bull.) BK Cui, ML Han and YC Dai [formerly Piptoporus betulinus Bull. P. Karst.-(birch polypore)] from the family of Fomitopsidaceae (Basidiomycota)

Katarzyna Sułkowska-Ziaja

katarzyna.sulkowska-ziaja@uj.edu.pl

1 Department of Pharmaceutical Botany, Faculty of Pharmacy, Jagiellonian University Medical College, Medyczna 9, 30-688 Kraków, Poland

2 Department of Pharmacognosy, Faculty of Pharmacy, Jagiellonian University Medical College, Medyczna 9, 30-688 Kraków, Poland

3 Department of Radioligands, Faculty of Pharmacy, Jagiellonian University Medical College, Medyczna 9, 30-688 Kraków, Poland is a common species of arboreal mushroom [1]. A characteristic feature of this species is the colonization of both living and dead individuals of Betula sp. genus. This is an inedible species; however, young fruiting bodies are suitable for consumption [2]. The oldest evidence of the use of $F$. betulina fruiting bodies by humans is the discovery of fragments with the remains of the ice man-Ötzi, who lived 5300 years ago $(3300 \mathrm{BC})$. This fact allows the conclusion that the fruiting bodies of this species were used for healing purposes [3]. The fruiting bodies of $F$. betulina have also been widely used in folk medicine due to their antimicrobial properties that accelerate wound healing. The fruiting bodies have also been employed as a laxative and adjuvant in stomach disorders [3]. Most of the potential therapeutic applications described above have been confirmed in scientific studies. Aqueous extracts and pentacyclic triterpenes isolated from fruiting bodies exhibit immunomodulatory and 
anticancer effects [4]. Ethanol-acetate extract and single triterpene derivatives of lanostane exhibit anti-inflammatory activity [5]. Another documented effect is its antioxidant activity and the ability to inhibit hyaluronidase, an enzyme depolymerizing hyaluronic acid and causing the inhibition of acetylcholinesterase, which is used in the symptomatic treatment of Alzheimer's disease [6].

An alternative method to obtain secondary metabolites with therapeutic properties from fruiting bodies is to use the biosynthetic capability of mycelial cultures. The main advantage of mycelial cultures is their independence from environmental conditions and their ability to continuously produce high-quality material; however, there may be differences in the chemical composition of mycelium and fruiting bodies [7].

The chemical composition of biomass extracts from mycelial cultures of $F$. betulina has so far only been studied to a limited extent. However, the anticancer properties of the extracts have been proven [8].

A challenge facing modern science are the so-called civilization diseases, which include cancer diseases. Inflammation, a factor often preceding the formation of a tumor, plays an important role in the process of oncogenesis and cancer progression. Studies have proved the existence of a feedback mechanism that allows chronic inflammation to be connected with metastasis. Inflammatory responses play decisive roles at different stages of tumor development, including initiation, promotion, malignant conversion, invasion, and metastasis [9]. This observation led us to study the cytotoxic and anti-inflammatory potential of extracts from fruiting bodies and from mycelial cultures of $F$. betulina.

The present study is the first to present a comparative analysis of groups of bioactive metabolites in extracts from fruiting bodies and from mycelial cultures. The multidirectional biological activity of extracts from fruiting bodies and biomass of $F$. betulina has so far been explained mainly by the activity of polysaccharides and triterpenes. A comprehensive understanding of the qualitative and quantitative profiles of the groups of metabolites (sterols, indole derivatives, phenolic acids and fatty acids) was established using chromatographic methods. In addition, for the first time, the cytotoxic and anti-inflammatory activities of the obtained extracts were compared using in vitro methods.

\section{Materials and methods}

The fruiting bodies were collected in 2014 in the mixed forests of northern Poland. Representative samples were deposited at the Department of Pharmaceutical Botany, Jagiellonian University Medical College, Kraków.

Mycelial cultures were isolated from the internal part of the fruiting bodies. Pieces of sporocarps were surface-sterilized with $70 \%$ ethanol for $2 \mathrm{~min}$. Then, these were rinsed three times with sterile water and placed on Oddoux medium [10]. Initial cultures were grown for three weeks at $22 \pm 2{ }^{\circ} \mathrm{C}$ under a $16 / 8 \mathrm{~h}$ light/dark period. The experimental cultures were maintained as submerged cultures on Oddoux medium. Medium was inoculated with 3 -week-old initial cultures. The cultures (three series) were maintained for 3 weeks, under the same light and temperature conditions as the initial cultures, on an Alltel rotary shaker operating at $140 \mathrm{rpm}$ with a vibration amplitude of $35 \mathrm{~mm}$. After separation from the medium, the obtained mycelium was frozen and lyophilized (lyophilizer Freezone 4.5 , Labconco, USA) at $-40^{\circ} \mathrm{C}$. After lyophilization, materials were ground in a mortar and used for chemical analyses.

\section{Extraction and HPLC analysis of phenolic acids}

Two grams of material was extracted by boiling methanol (at $67.4^{\circ} \mathrm{C}$ ) for $2 \mathrm{~h}$ under a reflux condensor. Combined extracts $(200 \mathrm{~mL})$ were concentrated to dryness using a rotary vacuum evaporator (Büchi) at $40{ }^{\circ} \mathrm{C}$. Residues were dissolved in $10 \mathrm{~mL}$ of methanol. The filtered sample (Millipore PTFE membrane, $0.45 \mu \mathrm{m})$ was injected $(20 \mu \mathrm{L})$ in an HPLC column. The HPLC method was followed according to a procedure described previously [11]. HPLC analyses were conducted using a Hitachi HPLC VWR apparatus: pump L-2130, RP-18e column ( $250 \mathrm{~mm} \times 4 \mathrm{~mm}, 5 \mu \mathrm{m})$ thermostated at $25{ }^{\circ} \mathrm{C}$, and diode array detector (DAD) L-2455 at UV range $200-400 \mathrm{~nm}$.

The gradient program was as follows: $0-20 \mathrm{~min}, 0 \% \mathrm{~B}$; 20-35 min, 0-20\% B; 35-45 min, 20-30\% B; 45-55 min, 30-40\% B; 55-60 min, 40-50\% B, 60-65 min, 50-75\% B; and $65-70 \mathrm{~min}, 75-100 \% \mathrm{~B}$, with a hold time of $15 \mathrm{~min}$, at $25{ }^{\circ} \mathrm{C}$. The flow rate was $1.0 \mathrm{~mL} / \mathrm{min}$. Comparison of UV spectra at $\lambda=254$ and retention times with standard compounds enabled identification of phenolic acids present in the analyzed samples. Phenolic acid standards were purchased from Fluka (Chemie AG) and Sigma (St. Louis, USA).

\section{Extraction and GC analysis of fatty acids}

One gram of material was extracted with a chloroform-methanol solution, 2:1 (v/v). Fatty acid methyl esters (FAME) were synthesized using $20 \% \mathrm{BF}_{3}$ in methanol at $100{ }^{\circ} \mathrm{C}$. FAME analyses were performed using gas chromatography (GC) on an Agilent $6890 \mathrm{~N}$ with a J and W DB-23 capillary column $(60 \mathrm{~m}$, ID $0.25 \mathrm{~mm}, 0.25 \mu \mathrm{m})$ and FID detector. Chromatography parameters-FID $260{ }^{\circ} \mathrm{C}$, injector $250{ }^{\circ} \mathrm{C}$, split ratio $50: 1$, oven $140{ }^{\circ} \mathrm{C}$ for 5 min -ranged from 140 to $190^{\circ} \mathrm{C}$ at $4{ }^{\circ} \mathrm{C} / \mathrm{min}, 190^{\circ} \mathrm{C}$ for $15 \mathrm{~min}$, and from 190 to $240{ }^{\circ} \mathrm{C}$ at $2.75{ }^{\circ} \mathrm{C} / \mathrm{min}, 240{ }^{\circ} \mathrm{C}$ for $4 \mathrm{~min}$, carrier 
gas-helium. For the identification of fatty acids, retention times of FAME standards from Supelco (47801) were used. Peak areas were measured with an integrator (ChemStation). The results for fatty acid (FA) composition, total saturated fatty acids (SFA), monounsaturated fatty acids (MUFA) and polyunsaturated fatty acids (PUFA) of the samples were expressed as relative $\%$ of total fatty acids.

\section{Extraction and HPLC analysis of sterols}

Five grams of material was extracted with a mixture of methanol/dichloromethane, 75:25 (v/v). The mixture was sonicated at $40 \mathrm{kHz}$ for $10 \mathrm{~min}$. After $2 \mathrm{~h}$, the extract was centrifuged at 12,000 rpm for $5 \mathrm{~min}$ and decanted. The extraction procedure was repeated twice and obtained extracts were mixed and evaporated under reduced pressure.

The filtered sample (Millipore PTFE membrane $0.45 \mu \mathrm{m}$ ) was injected $(20 \mu \mathrm{L})$ into the HPLC column. Analyses were conducted using a Hitachi HPLC VWR liquid chromatograph (Merck, Germany), as described above.

The HPLC method was followed according to the procedure developed by Yuan [12] with our own modifications concerning the gradient procedure. The mobile phase consisted of solvent A: methanol/water 80:20 (v/v), and solvent B: methanol/dichloromethane 75:25 (v/v The gradient program was as follows: $0-10 \mathrm{~min}, 80: 20 \% \mathrm{~B} ; 10-35 \mathrm{~min}$, 40-60\% B; 35-50 min, 0-100\% B; 50-55 min, 80-20\% B; with a hold time of $15 \mathrm{~min}$, at $25^{\circ} \mathrm{C}$ ). The flow rate was $1.0 \mathrm{~mL} / \mathrm{min}$. The chromatographic peaks were recorded at a wavelength of $280 \mathrm{~nm}$. Sterol standards were purchased from Fluka (Chemie AG).

\section{Extraction and HPLC analysis of triterpenoids}

One gram of material sample was mixed with $10 \mathrm{~mL}$ methanol $95 \%$ containing $1 \% \mathrm{HCl}$ conc. and then homogenized under sonication for $15 \mathrm{~min}$. After $30 \mathrm{~min}$, the extract was filtered through a paper and Millipore PTFE membrane $(0.45 \mu \mathrm{m})$.

The HPLC method was followed according to the procedure developed by Holonec [13]. The filtered sample was injected $(20 \mu \mathrm{L})$ into the HPLC column. HPLC analyses were conducted using a Hitachi HPLC VWR liquid chromatograph (Merck, Germany), as described above. An isocratic separation was applied, for which the mobile phase consisted of acetonitrile: water, 9:1, flow $1 \mathrm{~mL} / \mathrm{min}$. at temperature $25{ }^{\circ} \mathrm{C}$ and wavelength at $210 \mathrm{~nm}$. Triterpenoid standards were purchased from Sigma (St. Louis, USA).

\section{Determination of indole derivatives}

Five grams of material was extracted with $100 \mathrm{~mL}$ of methanol for $2 \mathrm{~h}$ in a magnetic stirrer. The obtained extracts were combined and concentrated to dryness. The HPLC method was carried out according to the procedure described by Muszyńska [14]. Briefly, the conditions were as follows: Hitachi HPLC; pump L-7100; column Purospher RP-18 $(250 \mathrm{~mm} \times 4 \mathrm{~mm}, 5 \mu \mathrm{m})$. Isocratic separation was used, and the mobile phase was: methanol: water: ammonium acetate 15:14:1 (v/v/v); flow $1 \mathrm{~mL} / \mathrm{min}$. Chromatographic peaks were recorded at a wavelength of $280 \mathrm{~nm}$. Indole standards were purchased from Sigma (St. Louis, USA).

\section{Cytotoxicity determination}

Five grams of material was extracted three times with $100 \mathrm{~mL}$ of methanol for $24 \mathrm{~h}$ in a magnetic stirrer. The obtained extracts were combined and concentrated to dryness.

A cytotoxicity determination was performed on human cancer cells and their corresponding normal cells. Prostate cancer and melanoma lines, grouped into panels, were used for this purpose. The prostate panel comprised DU145 cancer cells as well as normal epithelial cells of the prostate-PNT-2. The melanoma panel comprised the WM795 and A375 cell lines differing in metastatic potential as well as the reference normal cells of skin fibroblasts-BJ. All the cell lines were commercial (ATCC) and remained in a continuous culture at the Department of Pharmacognosy, Jagiellonian University Medical College (Poland). Cells were grown on media (DMEM F12, DMEM high glucose) with $10 \%$ bovine serum and a mixture of antibiotics in an incubator with $5 \% \mathrm{CO}_{2}$ at $37{ }^{\circ} \mathrm{C}$ and constant humidity. The cytotoxic activity of the tested extracts was measured with the LDH viability test, according to a procedure described previously [15]. Each experiment was repeated three times. The cytotoxicity of the samples was measured as follows: $\%$ cytotoxicity $=[($ Asample - Aspont $):($ Amax - Aspont $)] \times 100$ where Asample is the absorbance value for the cells treated with the tested substances, Aspont is the value for the spontaneous LDH release and Amax the value in lysed cells in the presence of Triton $\times 100$.

\section{Anti-inflammatory activities}

\section{Cell cultures}

A549 Human Lung Carcinoma Epithelial Cells (CCL-185, ATTC, Manassas, VA, USA) were cultured as described previously [16]. Cells were activated by LPS $1 \mu \mathrm{g} / \mathrm{mL}$ for $24 \mathrm{~h}$. After this time, lung epithelial cells were incubated with $10 \mu \mathrm{L}$ or $25 \mu \mathrm{L}$ of methanolic extract from biomass and fruiting bodies for $24 \mathrm{~h}$. 


\section{Western blot}

Cell lysates were prepared and subjected to $10 \%$ SDS-polyacrylamide gel electrophoresis, as described earlier [16]. The experiments used primary antibodies anti-cyclooxygenase 2 (COX-2) and anti- $\beta$-actin (GeneTex Inc., Irvine, CA, USA), diluted 1:1000 and the secondary antibody anti-rabbit IgG (HRP) diluted 1:2000 (ThermoFisher Scientific, Waltham, MA, USA). The integrated optical density of the bands was quantified using a Chemi Doc Camera with Image Lab software (Bio-Rad, Hercules, CA, USA).

\section{Statistical analysis}

Values are presented as means \pm SD. All experiments were performed four times. Using one way ANOVA with Tukey-Kramer post hoc method of multiple comparisons, statistical analysis of the data was performed. The value $\mathrm{p}<0.05$ was accepted as the level of statistical significance.

\section{Results and discussion}

The use of mycelial cultures of macrofungi for experimental and medical purposes is a promising and reproducible method that enables efficient production of fungal biomass and its metabolites [17]. Differences in the content of bioactive compounds in fruiting bodies derived from natural sites may result not only from genetic differences between populations, but also from different habitats and environmental conditions during growth and development. Differences in the amounts of bioactive compounds such as polysaccharides, terpenoids, steroids and phenolic compounds are much lower under the controlled, reproducible conditions of mycelial cultures.

After a 3-week growth cycle, the biomass increments were on average $9.5 \mathrm{~g}$ dry mass per liter. Obtained biomass increments and growth dynamics did not differ from the results obtained previously by other researchers [18]. The applied methods for extraction and HPLC analysis provided the opportunity to obtain optimal conditions for the qualitative and quantitative determination of selected compounds in the examined material. Previous analysis of the chemical composition of fruiting bodies of $F$. betulina had demonstrated that they mainly contain carbohydrates, terpene compounds, sterols, fatty acids and aromatic compounds [19]. Chemical biomass composition has so far been studied only to a limited extent.

In contrast, biological activity studies have focused on extracts. Cyranka et al. demonstrated that the type of mycelial extract has an effect on the growth and viability of colon adenocarcinoma cells [8]. Moreover Pleszczyńska et al. showed the anti-proliferative and anti-immigration properties of water and ethanol extracts from fruiting bodies against human cancer cells [20].

The total content of phenolic acids in the biomass obtained from mycelial cultures was $22.56 \mathrm{mg} / 100$ dry mass (DM.). The total content of phenolic acids in fruiting bodies was $37.08 \mathrm{mg} / 100 \mathrm{DM}$. Syringic, gallic, 5-hydroxybenzoic and 3,4-dihydrophenylacetic acids were determined in mycelium and fruiting bodies (Table 1).

Phenolic acids identified both in fruiting bodies and mycelial culture show a broad spectrum of biological activity of antioxidant, antibacterial, antiviral, antifungal and anti-inflammatory nature. Particularly noteworthy is the antioxidant activity of phenolic acids. A deficiency of these acids induces the human body into a state of chronic oxidative stress, the consequence of which may be chronic inflammation that leads to the development of many diseases.

Syringic acid determined in mycelial cultures also exhibits a choleretic activity, while in turn gallic acid possesses antiseptic, astringent and antiperspirant activity.

The most common phenolic acids in fruiting bodies of higher mushrooms include protocatechuic acid, gallic acid, $p$-hydroxybenzoic acid, gentisic acid, caffeic acid, and syringic and vanillic acids. Veratryl, $p$-coumaric, caffeic, ferulic or cinnamic acids are less common [21]. Phenolic acids are compounds important for the survival of fungal organisms, as evidenced by the various biogenetic pathways leading to their formation. Similar to the situation in plants, phenolic acids play a defensive role against parasites and microorganisms in mushrooms. Their insecticidal, anti-bacterial and anti-microbial properties are known [22].

In both mycelium and fruiting bodies eleven fatty acids were identified. The results of the analysis are presented in Table 2.

The amounts of individual compounds were within a wide range-from about $35.8 \%$ (palmitic acid) to $0.4 \%$ (palmitooleic acid)—in the extracts obtained from biomass. In turn, in extracts from fruiting bodies, the amounts range from $41.6 \%$ (stearic acid) to $0.4 \%$ (cis-10-pentadecanoic acid). The amount of palmitic acid is 2.5 -fold higher, and that of myristoleic acid is ninefold higher in extracts obtained from biomass than in extracts from fruiting bodies. However, most interesting is the fact that the concentration of linoleic acid is up to 23 -fold higher in extracts obtained from mycelial biomass cultures than in extracts of fruiting bodies.

Linoleic acid (LA) belongs to the group of essential fatty acids (EFAs). It is a precursor of arachidonic acid, the component of bile and octen-3-ol which gives mushrooms their characteristic aroma. In addition, LA reduces the total fat in the blood and, as a result, reduces the risk of cardiovascular diseases $[15,16]$. A high intake of dietary n-6 polyunsaturated fatty acid contributes to excess chronic inflammation. For linoleic acid (LA), as a precursor of long-chain fatty acids from the $n-6$ family, there is no evidence that a high 
Table 1 Quantitative comparison of studied groups of compounds in fruiting bodies and biomass of Fomitopsis betulina

Table 2 Quantitative comparison of fatty acids in fruiting bodies and biomass of Fomitopsis betulina

\begin{tabular}{lcc}
\hline Name of compounds & Amounts of compounds $[\mathrm{mg} / 100 \mathrm{~g} \mathrm{DM}]$ \\
\cline { 2 - 3 } & Fruit bodies & $\begin{array}{c}\text { Biomass from } \\
\text { mycelial cultures }\end{array}$ \\
\hline Non hallucinogenic indole derivatives & & \\
L-Tryptophan & $2.03 \pm 0.83^{\mathrm{a}}$ & $1.34 \pm 0.28^{\mathrm{a}}$ \\
5-Hydroxy-L-tryptophan & $3.05 \pm 1.02^{\mathrm{a}, \mathrm{b}}$ & $2.74 \pm 0.62$ \\
5-Methyltryptamine & $5.25 \pm 1.6^{\mathrm{a}, \mathrm{b}}$ & $3.99 \pm 0.95^{\mathrm{a}}$ \\
Phenolic acids & & $1.08 \pm 0.74^{\mathrm{a}}$ \\
Syringic acid & $0.99 \pm 0.86^{\mathrm{a}}$ & $4.02 \pm 1.01^{\mathrm{a}, \mathrm{b}}$ \\
Gallic acid & $7.55 \pm 1.30^{\mathrm{a}, \mathrm{b}}$ & $9.11 \pm 1.29^{\mathrm{a}, \mathrm{b}}$ \\
5-Hydroxybenzoic acid & $10.88 \pm 1.20^{\mathrm{a}, \mathrm{b}, \mathrm{c}}$ & $8.04 \pm 0.98^{\mathrm{a}, \mathrm{b}}$ \\
3,4-Dihydrophenylacetic acid & $6.55 \pm 0.82^{\mathrm{a}, \mathrm{c}}$ & \\
Triterpenes & & $0.0006 \pm 0.00022$ \\
Betulin & $0.00209 \pm 0.00102$ & $0.00031 \pm 0.00037$ \\
Betulinic acid & $0.00085 \pm 0.00068$ & \\
Sterols & & $41.29 \pm 2.87^{\mathrm{a}}$ \\
Ergosterol & $103.99 \pm 2.63^{\mathrm{a}}$ & $4.01 \pm 1.75^{\mathrm{a}, \mathrm{b}}$ \\
Hexestrol & $3.55 \pm 0.71^{\mathrm{a}, \mathrm{b}}$ & $17.11 \pm 1.50^{\mathrm{a}, \mathrm{b}, \mathrm{c}}$ \\
Ergosterol peroxide & $11.88 \pm 0.87^{\mathrm{a}, \mathrm{b}, \mathrm{c}}$ & $0.31 \pm 0.30^{\mathrm{a}, \mathrm{c}}$ \\
Cholecalciferol & $6.55 \pm 0.04^{\mathrm{a}, \mathrm{b}, \mathrm{c}}$ & \\
\hline
\end{tabular}

Data are presented as the mean \pm SD (standard deviation); $n=3$ repetitions. Tukey test was used to reveal the differences between paired groups of elements in rows, the same letters $(\mathrm{a}, \mathrm{b}, \mathrm{c})$ are marked for which the content differences are statistically significant (for $p$ values $<0.05)$; (GraphPad InStat)

\begin{tabular}{llcc}
\hline Common names of fatty acids & Lipid numbers & Amounts of fatty acids [\%] \\
\cline { 4 - 4 } & & Extract from fruit bodies & Extract from in vitro cultures \\
\hline SFA & & $5.42 \pm 1.76^{\mathrm{a}}$ & $1.06 \pm 0.01^{\mathrm{a}}$ \\
Capric acid & C10:0 & $14.13 \pm 1.75^{\mathrm{a}, \mathrm{b}}$ & $0.59 \pm 0.09^{\mathrm{a}, \mathrm{b}}$ \\
Lauric acid & $\mathrm{C} 12: 0$ & $1.29 \pm 0.1^{\mathrm{b}, \mathrm{c}}$ & $0.67 \pm 0.29^{\mathrm{a}, \mathrm{c}}$ \\
Myristic acid & $\mathrm{C} 14: 0$ & $29.53 \pm 2.73^{\mathrm{a}, \mathrm{b}, \mathrm{c}, \mathrm{d}}$ & $0.91 \pm 0.47^{\mathrm{a}, \mathrm{d}}$ \\
Pentadecanoic acid & $\mathrm{C} 15: 0$ & $13.82 \pm 2.50^{\mathrm{a}, \mathrm{c}, \mathrm{d}, \mathrm{e}}$ & $35.8 \pm 1.53^{\mathrm{b}, \mathrm{c}, \mathrm{d}, \mathrm{e}}$ \\
Palmitic acid & $\mathrm{C} 16: 0$ & $41.60 \pm 3.03^{\mathrm{a}, \mathrm{b}, \mathrm{c}, \mathrm{d}, \mathrm{e}}$ & $17.01 \pm 0.98^{\mathrm{b}, \mathrm{c}, \mathrm{d}, \mathrm{e}}$ \\
Stearic acid & $\mathrm{C} 18: 0$ & & \\
MUFA & & $1.71 \pm 0.87^{\mathrm{a}}$ & $15.30 \pm 2.96^{\mathrm{a}}$ \\
Myristoleic acid & $\mathrm{C} 14: 1 \mathrm{n} 5$ & $2.82 \pm 1.84^{\mathrm{b}}$ & $0.42 \pm 0.64^{\mathrm{a}}$ \\
Palmitooleic acid & $\mathrm{C} 16: 1 \mathrm{c}$ & $40.78 \pm 2.46^{\mathrm{a}, \mathrm{b}, \mathrm{c}}$ & $2.86 \pm 0.08^{\mathrm{a}}$ \\
Oleic acid & C18:1w9 & $0.43 \pm 0.57^{\mathrm{c}}$ & $0.55 \pm 0.53^{\mathrm{a}}$ \\
Cis-10-pentadecanoic acid & C15:1 & & \\
PUFA & & $1.1 \pm 0.95$ & $25.3 \pm 0.82$ \\
Linoleic acid & C18:2w6 &
\end{tabular}

Data are presented as the mean \pm SD (standard deviation); $n=3$ repetitions. Tukey test was used to reveal the differences between paired groups of elements in rows, the same letters (a,b,c,d,e) are marked for which the content differences are statistically significant (for $p$ values $<0.05)$; (GraphPad InStat) intake of LA with the diet influences the level of inflammatory markers in blood [23].

Fatty acids contained in mushrooms may support antiinflammatory processes in the human organism, due to the high content of unsaturated fatty acids [24, 25].
Polyunsaturated fatty acids (PUFAs) are precursors of eicosanoids, signaling molecules necessary for proper regulation of cellular processes in muscles, blood vessels, nerve cells and in the immune system. Eicosanoids provide a balance between inflammatory and anti-inflammatory processes 
[26]. PUFAs include the n-3, n-6 and n-9 series acids. Maintaining the correct proportions of fatty acids from the $n-3$ to $\mathrm{n}-6$ series in the diet is crucial in preventing the development of cardiovascular diseases or cancers. $\alpha$-Linolenic acid (ALA) is an essential ingredient in normal nutrition; it is a precursor to the long-chain PUFAs of the $\mathrm{n}-3$ series. It also exhibits anti-inflammatory activity [27].

Sterols determined in mycelial cultures of $F$. betulina included ergosterol $(41.29 \mathrm{mg} / 100 \mathrm{~g} \mathrm{D}$.), cholecalciferol (0.30 g DM), ergosterol peroxide and hexestrol. The results of the quantitative analysis are presented in Table 1.

Sterols are common ingredients of fruiting bodies of most Basidiomycota representatives. The most common is ergosterol. Ergosterol and its peroxide are essential for the proper development of the hyphae of higher fungi. Ergosterol (provitamin $\mathrm{D}_{2}$ ) is one of the main components of fungal cell membranes. It has anti-cancer and immunostimulating properties and is also a precursor of cortisol, an adrenal hormone with anti-inflammatory activity.

Numerous studies have shown that ergosterol and its peroxidation products (ergosterol peroxide) show a therapeutic effect by reducing the pain related to inflammation, reducing the incidence of cardiovascular disease and inhibiting the action of cyclooxygenase enzymes (COX) [28]. Ergosterol present in the fruiting bodies of edible mushrooms (e.g., Imleria badia and A. bisporus) has an anti-inflammatory and anticancer activity [19]. Anti-inflammatory properties in the mouse model have also been demonstrated for Lentinula edodes extract, which is rich in ergosterol. Supplementation with L. edodes extract enriched with vitamin D using UV-B radiation in C57B1/6 mice with mitogen-induced (concanavalin A) liver inflammation causes a significant reduction in liver damage. The histopathological image of tissues is improved and also the plasma level of transaminases and INF- $\gamma$ decreased. In addition, the anti-inflammatory effect of vitamin D and fungal extract is synergistic [29].

In the study material, three indole derivatives were determined: 5-hydroxy-L-tryptophan, 5-methyltryptamine and L-tryptophan in the both type of extracts.. Quantitative results are presented in Table 1. The largest amount was found in the case of 5-methyltryptamine $(3.99 \mathrm{mg} / 100 \mathrm{~g} \mathrm{DM}$ in mycelial cultures), while the smallest was for L-tryptophan $(1.34 \mathrm{mg} / 100 \mathrm{~g}$ DM on in mycelial cultures). The total content of indole compounds in the biomass was $8.07 \mathrm{mg} / 100 \mathrm{~g}$ $\mathrm{DM}$ and in the fruiting bodies $10.33 \mathrm{mg} / 100 \mathrm{~g} \mathrm{DM}$.

L-tryptophan and 5-hydroxy-L-tryptophan identified in mycelial cultures are observed in in vitro cultures of numerous edible species of Sarcodon imbricatus, I. badia and Cantharellus cibarius [30-32]. The concentrations of these two indole derivatives are higher in the mycelial cultures of the above-mentioned species than in the cultures of $F$. betulina, with the exception of I. badia cultures. The concentration of 5-hydroxytryptophan in the mycelium of this species was lower than $1 \mathrm{mg} / 100 \mathrm{~g} \mathrm{DM}$, whereas in $F$. betulina its content was $2.738 \mathrm{mg} / 100 \mathrm{~g} \mathrm{DM}$ 5-Methyltryptamine, present at a concentration of $3.99 \mathrm{mg} / 100 \mathrm{~g} \mathrm{DM}$ in the mycelium of $F$. betulina, is virtually not noted in the fruiting bodies of L. edodes and Leccinum scabrum [33]. L-Tryptophan and 5-hydroxytryptophan have a sleep-depriving effect and support the treatment of depression. They are also precursors of serotonin and melatonin-endogenous substances responsible for regulating the circadian cycle of our body. Serotonin also has proven antioxidant and anti-cancer properties.

Chromatographic analysis showed the presence of two peaks characteristic of betulin and betulinic acid. HPLC chromatogram of triterpenes separation in mycelial cultures shows Fig. 1. In fruiting bodies, the content of betulin and betulinic acid was 0.0006 and $0.00031 \mathrm{mg} / 100 \mathrm{~g} \mathrm{DM}$, respectively, while in mycelial cultures it was 0.00209 and $0.00085 \mathrm{mg} / 100 \mathrm{~g}$ DM (Table 1). In addition, betulin was isolated and spectrophotometrically identified in biomass. The existence of betulin was confirmed by the presence of the following signals: ${ }^{1} \mathrm{H}$ NMR $(300 \mathrm{MHz}, \mathrm{CHLORO}-$ FORM-d) d ppm $4.68(1 \mathrm{H}, \mathrm{d}, \mathrm{J}=2.34 \mathrm{~Hz}), 4.58(1 \mathrm{H}$, dd, $\mathrm{J}=2.34,1.17 \mathrm{~Hz}), 3.79(1 \mathrm{H}, \mathrm{dd}, \mathrm{J}=10.55,1.76 \mathrm{~Hz}), 3.33$ $(1 \mathrm{H}, \mathrm{d}, \mathrm{J}=10.55 \mathrm{~Hz}), 3.18(1 \mathrm{H}, \mathrm{dd}, \mathrm{J}=10.84,4.98 \mathrm{~Hz})$, $2.38(1 \mathrm{H}, \mathrm{td}, \mathrm{J}=10.70,5.57 \mathrm{~Hz}), 1.68$ (s), 1.02 (s), 0.98 (s), 0.97 (s), 0.82 (s), 0.76 (s).

For example, in fruiting bodies of another arboreal species of mushroom Inonotus obliquus, the content of betulinic acid and betulin was determined at $103.0 \mathrm{mg} / \mathrm{g}$ and $1490.0 \mathrm{mg} / \mathrm{g}$ respectively [34].

Betulin exhibits a broad spectrum of biological activity with respect to many diseases, including anticancer activity. It interacts with Sterol Regulatory Element-Binding Proteins (SREBP), which participates in the activation of the expression of genes involved in the synthesis of cholesterol, fatty acids and triglycerides [35]. Compounds from the group of terpenoids with anti-inflammatory, antiproliferative and anticancer potential have been isolated from numerous species of mushrooms living on wood. One of these is Poria cocos. An anti-inflammatory activity of extracts from this mushroom species has been demonstrated in an in vitro model using RAW 264.7 macrophages. A decrease in the generation of pro-inflammatory mediators by inactivating the NF- $\mathrm{KB}$ signaling pathway was observed [36].

In turn, the anticancer activity of fungal terpenoids was tested on the U937 line. The concentration and time-dependent antiproliferative effect and pro-apoptotic effects of the examined extracts is related to the release of cytochrome $\mathrm{C}$ to the cytosol, activation of caspases $-3,-8$ and -9 , degradation of PARP and mitochondrial membrane potential loss. The obtained results indicate the potential of $P$. cocos in the treatment of leukemia [37]. A series of triterpenes with a similar inhibitory effect on the NF- $\mathrm{KB}$ signaling pathway has been isolated from another species, Inonotus obliquus 


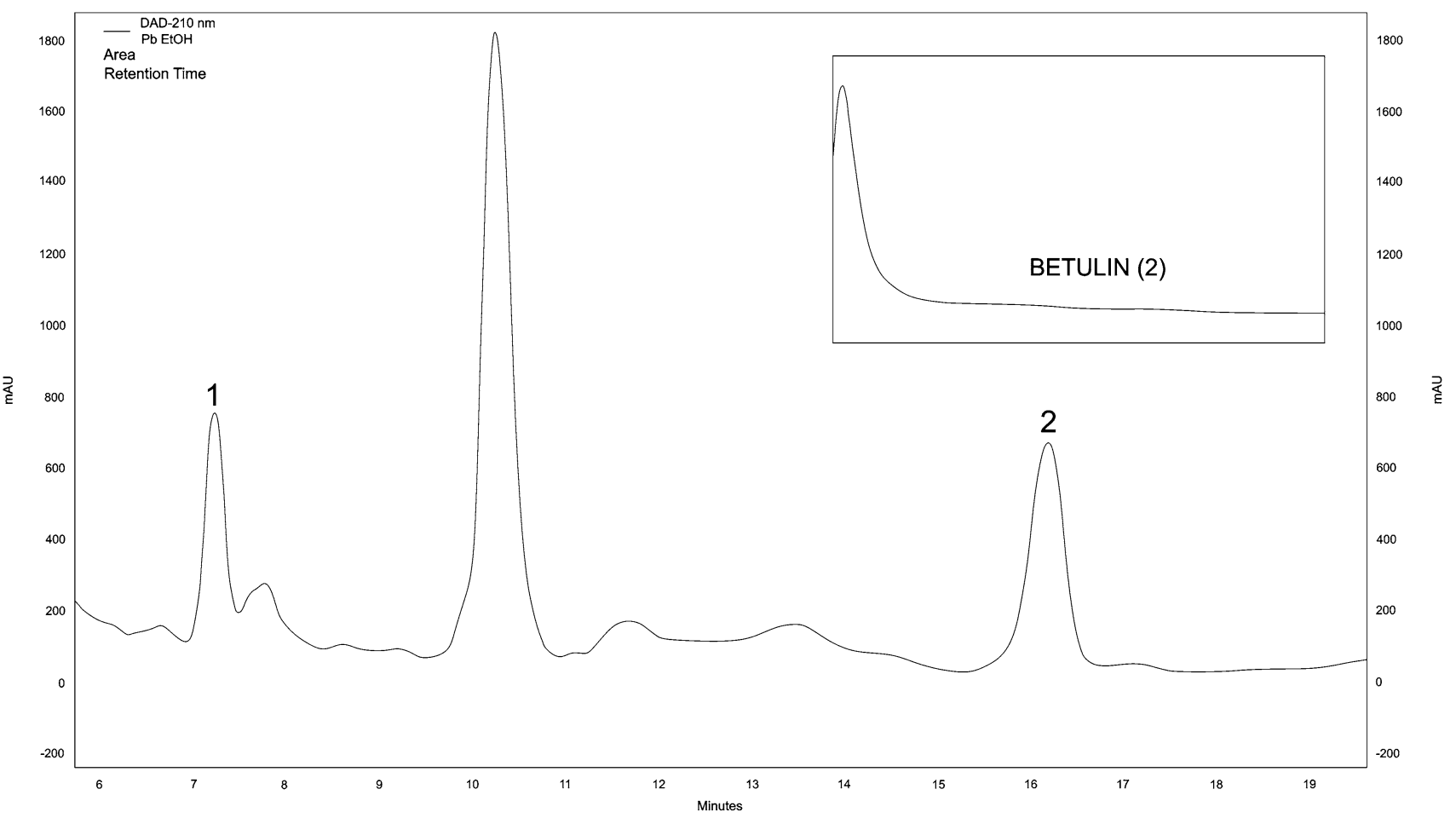

Fig. 1 HPLC chromatographic separation of triterpenoids from mycelial culture of 1 -betulinic acid, 2-betulin. UV spectrum of betulin

[38]. In turn, the extracts from Antrodia camphorata inhibit the proliferation of cancer cells, and also show a reduction of NO, TNF- $\alpha$ and IL-12 [39].

All examined extracts revealed varied cytotoxic effects against the cell lines used in the experiment. The mycelium extract exhibited significant cytotoxic activity against DU145 prostate cancer cells $(27.28 \pm 0.98$ and $5.37 \pm 0.31 \%$ of viable cells at 20 and $50 \mu \mathrm{g} / \mathrm{mL}$, respectively) and a moderate effect was observed against A375 melanoma cell lines $(21.39 \pm 1.4 \%$ of viable cells at $50 \mu \mathrm{g} / \mathrm{mL})$, while the other melanoma cell line, WM795, seemed to be less vulnerable, with $74.21 \pm 1.29 \%$ of viable cells at $50 \mu \mathrm{g} / \mathrm{mL}$. Most importantly, the extract had no cytotoxic effect on normal human skin fibroblasts and prostate epithelial cells, which indicates its selectivity. The results of the cytotoxic effect of fruiting body extracts indicated a moderate influence on the viability of A375 melanoma and DU145 prostate cancer cells $(52.12 \pm 1.45$ and $69.32 \pm 1.69 \%$ of viable cells at $50 \mu \mathrm{g} / \mathrm{mL}$, respectively), while no impact was observed on WM795 melanoma cells $(96.22 \pm 1.63 \%$ of viable cells at $50 \mu \mathrm{g} / \mathrm{mL}$ ). Normal human skin fibroblasts were unaffected by the extract, but a strong cytotoxic effect was observed on normal prostate epithelial cells $(5.21 \pm 0.43 \%$ of viable cells at $50 \mu \mathrm{g} / \mathrm{mL}$ ) (Figs. 2, 3). The cause of differences in the cytotoxicity of extracts obtained from fruiting bodies and mycelial cultures can be related to the different chemical composition of the material in vitro and in vivo. Extracts

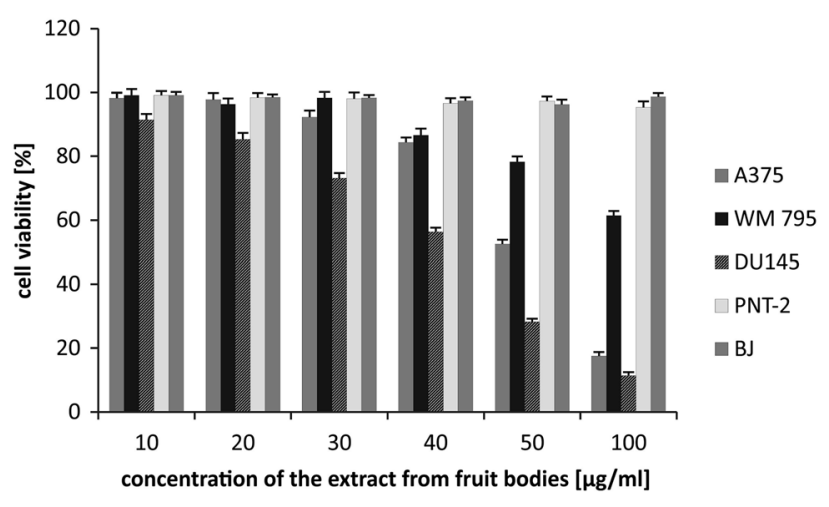

Fig. 2 Cytotoxic activity of extracts from fruiting bodies of Fomitopsis betulina

from fungal cultures possess a higher content of biological active sterols or triterpenoids.

Extracts obtained from fruiting bodies show higher activity, with respect to normal prostate cells, in relation to cultures, while cultures have a stronger influence on melanomas, especially A375, and to a lesser extent WM795. To the best of our knowledge, our study is the first to demonstrate the cytotoxic potential of mycelial cultures of $F$. betulina on prostate cancer and melanoma cells, while we have been able to find only one similar experiment on the cytotoxic activity of the mycelium (i.e. Cyranka et al.) against human colon 


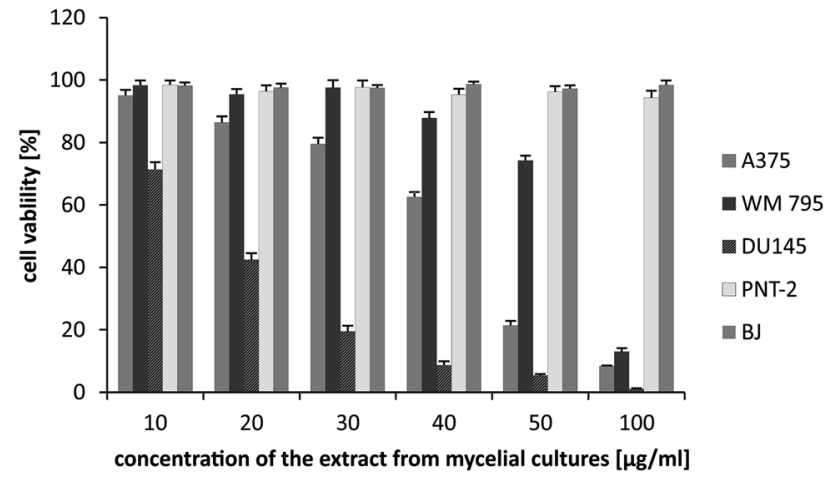

Fig. 3 Cytotoxic activity of extracts from mycelial culture of Fomitopsis betulina

cancer LS180 and normal CCD 841 CoTr cells. Ether and ethanolic extracts of the tested mushroom revealed selective cytotoxic and antiproliferative activity against cancer cells, with almost no impact on normal colon cells [8].

Some authors have described the impact of $F$. betulina fruiting bodies on a number of murine and human cancer cell lines. Kaczor et al. demonstrated a significant cytotoxic activity of the ether extract on FTC238 human thyroid carcinoma, SK-N-AS neuroblastoma, T47D breast carcinoma, Hep-2 larynx carcinoma and HeLa cervix carcinoma, in a time- and dose-dependent manner, with the most profound effect being for FTC238 cells. Moreover, the tested extract induced cell cycle arrestment in S-phase for thyroid carcinoma cells [40].

In a study by Tomasi et al., the moderate cytotoxic effect of methanolic extract of $F$. betulina fruiting bodies was observed against 3 LL murine Lewis lung carcinoma and L1210 lymphocytic leukaemia cells, with IC50 values of 88.2 and $77.5 \mu \mathrm{g} / \mathrm{mL}$, respectively [41].

Ethanolic extract from $F$. betulina fruiting bodies was also tested against human colon epithelial cells- $\mathrm{CaCo}-2$ and HT-29—by Doskocil et al., and the results showed that the extract was cytotoxic against HT-29 (IC50 $73 \mu \mathrm{g} / \mathrm{mL}$ ), but not $\mathrm{CaCo}-2$ cells [42].

Thus, the results of our study are comparable with those of other authors. Moreover, this is the first study to describe the cytotoxic impact of $F$. betulina fruiting bodies against prostate cancer and melanoma cells.

In the A549 cells incubated with extracts from fruiting bodies and mycelial cultures of $F$. betulina was determined using Western Blot technique, the expression of a COX-2 protein associated with the inflammatory process. As an internal control, glyceraldehyde 3-phosphate dehydrogenase (GAPDH) was used.

No apoptosis or reduced viability of A549 cells was observed after incubation with fruiting bodies and mycelium extracts in LPS-activated cells. The highest expression

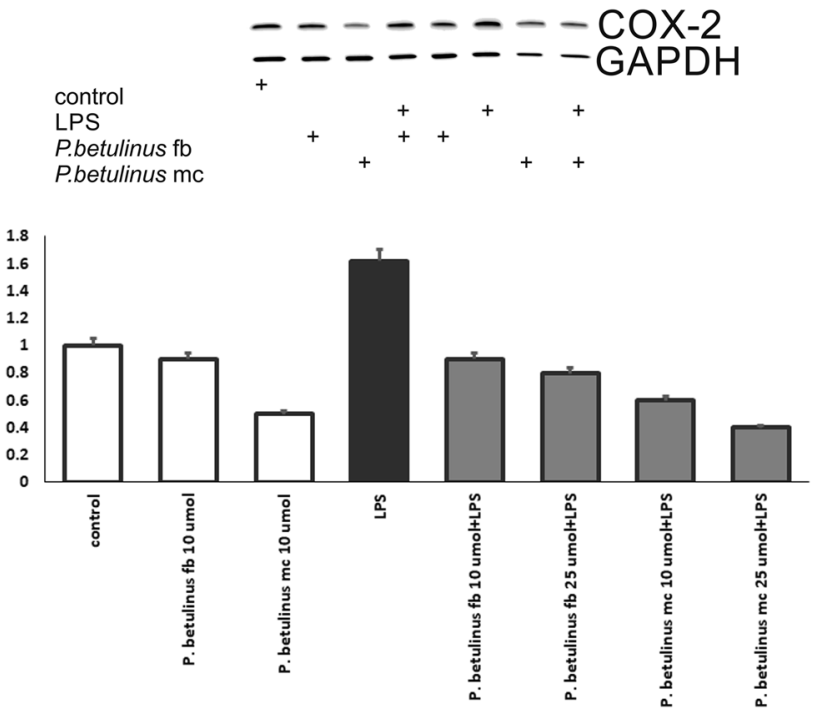

Fig. 4 Relative expression of COX-2 in A549 cells supplemented with extracts from fruiting bodies (fb) and mycelial cultures (mc) and activated with LPS

of COX-2 was observed in LPS activated A549 cells compared to the control. Cyclooxygenase expression was lower in samples incubated with mycelium extracts of $10 \mu \mathrm{M}$ and $25 \mu \mathrm{M}$ activated with LPS compared to extracts from fruiting bodies (Fig. 4).

The primary and secondary metabolites contained in the mushrooms exhibit a beneficial effect on immune system functioning: primarily anti-inflammatory and antioxidant activity. Natural products containing bioactive compounds with the mentioned effect can be used to reduce oxidative damage and inflammation in the human body. Chemical compounds contained in mushrooms also affect the proliferation and differentiation of lymphocyte populations, as well as the migration and adhesion of these cells. They can also inhibit the synthesis of inflammation mediators, i.e. cytokines, interleukins, prostaglandins, or nitric oxide by inhibiting the pro-inflammatory signal pathways associated with NF- $\kappa B$ nuclear receptors [43].

Our study on the anti-inflammatory activity of extracts of both fruiting bodies and mycelium includes anti-inflammatory compounds that can be used in the development of new anti-inflammatory drugs.

Numerous studies indicate that compounds with a lantostanoid structure possess an anti-inflammatory activity. Wangun et al. isolated and fully characterized three compounds with lanostanoid structures which demonstrated cyclooxygenase I inhibition activity, and in addition these compounds proved to be promising anti-inflammatory agents by inhibiting 3 - $\alpha$-hydroxysteroid dehydrogenase. Numerous studies on anti-inflammatory activity have focused on an analysis of extracts obtained from fruiting bodies. Methanol 
extracts from Pleurotus pulmonarius evoke an effect similar to diclofenac, while methanol extract from oyster mushroom causes inflammation of blood vessels [44].

Edible species have been widely studied in terms of antiinflammatory activity. The study conducted by Muszyńska et al. demonstrated the effect of I. badia extracts derived from biomass on simultaneous expression of COX-2, cPGES and GSTM1 proteins and the activity of NF-кB and PPAR $\gamma$ transcription factors in RAW 264.7 macrophages. High levels of expression of COX-2 and cPGES2 pro-inflammatory proteins and AHR proteins in LPS activated A549 cells have been found in $C$. cibarius species, and the addition of $C$. cibarius biomass extracts enriched with zinc salts inhibited the expression of the examined proteins $[16,45]$.

\section{Conclusion}

To the our best knowledge this study for a first time present a comparison of qualitative and quantitative data regarding bioactive secondary metabolites in the fruiting bodies and biomass of $F$. betulina, as well as results of in vitro antiinflammatory and cytotoxic activity against melanoma and prostate cell lines. Despite records of the use of this species in folk medicine, there has not been any previous characterization of the chemical or pharmacological potential of mycelial cultures. The results of biological activity assays demonstrate that extracts from $F$. betulina show cytotoxic and anti-inflammatory activities at different magnitudes of potency. The mycelial culture extract might be a potential supporting agent in prostate cancer therapy, but further studies are needed.

Acknowledgements The authors wish to thank Grzegorz Żuchowski $\mathrm{PhD}$ for conducting analyses using nuclear magnetic resonance spectroscopy (Mercury-VX $300 \mathrm{MHz}$, Varian).

Funding This study was funded by Polish Ministry of Science and Higher Education (Grant No. K/ZDS/007859).

\section{Compliance with ethical standards}

Conflict of interest The authors declare that they have no conflicts of interests.

Research involving human participants or animals This article does not describe any studies on human participants or animals performed by any of the authors.

Open Access This article is distributed under the terms of the Creative Commons Attribution 4.0 International License (http://creativeco mmons.org/licenses/by/4.0/), which permits unrestricted use, distribution, and reproduction in any medium, provided you give appropriate credit to the original author(s) and the source, provide a link to the Creative Commons license, and indicate if changes were made.

\section{References}

1. Han M-L, Chen Y-Y, Shen L-L, Song J, Vlasák J, Dai Y-C, Cui B-K (2016) Taxonomy and phylogeny of the brown-rot fungi: Fomitopsis and its related genera. Fungal Divers 80:343-373. https://doi.org/10.1007/s13225-016-0364-y

2. La Barre W (1970) Soma: divine mushroom of immortality. Harcourt Brace Jovanovich, New York

3. Poder R (2005) The ice man's fungi: facts and mysteries. Int $\mathbf{J}$ Med Mushrooms 7:357-359. https://doi.org/10.1615/IntJMedMus hr.v7.i3.190

4. Shamtsyan M, Konusova V, Maksimova Y, Goloshchev A, Panchenko A, Simbirtsev A, Petrishchev N, Denisova N (2004) Immunomodulating and anti-tumor action of extracts of several mushrooms. J Biotechnol 113:77-83. https://doi.org/10.1016/j. jbiotec.2004.04.034

5. Kamo T, Asanoma M, Shibata H, Hirota M (2003) Anti-inflammatory lanostane-type triterpene acids from Piptoporus betulinus. J Nat Prod 66:1104-1106. https://doi.org/10.1021/np0300479

6. Orhan I, Üstün O (2011) Determination of total phenol content, antioxidant activity and acetylcholinesterase inhibition in selected mushrooms from Turkey. J Food Compos Anal 24:386-390. https ://doi.org/10.1016/j.jfca.2010.11.005

7. Sułkowska-Ziaja K, Szewczyk A, Gdula-Argasińska J, Ekiert H, Jaśkiewicz J, Muszyńska B (2016) Chemical compounds of extracts from Sarcodon imbricatus at optimized growth conditions. Acta Mycol 51:1-11. https://doi.org/10.5586/am.1086

8. Cyranka M, Graz M, Kaczor J, Kandefer-Szerszen M, Walczak K, Kapka-Skrzypczak L, Rzeski W (2011) Investigation of antiproliferative effect of ether and ethanol extracts of birch polypore medicinal mushroom, Piptoporus betulinus (Bull.:Fr.) P. Karst. (Higher Basidiomycetes) in vitro grown mycelium. Int J Med Mushrooms 13:525-533. https://doi.org/10.1615/IntJMedMus hr.v13.i6.40

9. Grivennikov SI, Greten FR, Karin M (2010) Immunity, inflammation, and cancer. Cell 140:883-899. https://doi.org/10.1016/j. cell.2010.01.025

10. Oddoux L (ed) (1957) Recherches sur les mycéliums secondaires des Homobasidiés en culture pure. Imprimerie de Trevoux, Lyon

11. Ziaja K, Maślanka A, Szewczyk A, Muszynska B (2017) Physiologically active compounds in four species of phellinus. Nat Prod Commun 12:363-366

12. Yuan JP, Kuang HC, Wang JH, Liu X (2008) Evaluation of ergosterol and its esters in the pileus, gill, and stipe tissues of agaric fungi and their relative changes in the comminuted fungal tissues. Appl Microbiol Biotechnol 80:459-465. https://doi.org/10.1007/ s00253-008-1589-9

13. Holonec L, Ranga F, Crainic D, Truţa A, Socaciu C (2012) Evaluation of betulin and betulinic acid content in birch bark from different forestry areas of Western Carpathians. Not Bot Horti Agrobot Cluj-Napoca 40:99-105. https://doi.org/10.15835/nbha4 027967

14. Muszyńska B, Sułkowska-Ziaja K, Ekiert H (2011) Indole compounds in fruiting bodies of some edible Basidiomycota species. Food Chem 125:1306-1308. https://doi.org/10.1016/j.foodc hem.2010.10.056

15. Grabowska K, Podolak I, Galanty A, Żmudzki P, Koczurkiewicz P, Piska K, Pękala E, Janeczko Z (2017) Two new triterpenoid saponins from the leaves of Impatiens parviflora DC. and their cytotoxic activity. Ind Crops Prod 96:71-79. https://doi. org/10.1016/j.indcrop.2016.11.022

16. Grzywacz A, Argasinska JG, Kala K, Opoka W, Muszynska B (2016) Anti-inflammatory activity of biomass extracts of the Bay Mushroom, Imleria badia (Agaricomycetes), in RAW 264.7 cells. 
Int J Med Mushrooms 18:769-779. https://doi.org/10.1615/IntJM edMushrooms.v18.i9.20

17. Elisashvili V (2012) Submerged cultivation of medicinal mushrooms: bioprocesses and products (review). Int J Med Mushrooms 14:211-239. https://doi.org/10.1615/IntJMedMushr.v14.i3.10

18. Muszyńska B, Sułkowska-Ziaja K, Ekiert H (2009) Indole compounds in fruiting bodies of some selected Macromycetes species and in their mycelia cultured in vitro. Pharmazie 64:479-480

19. Kalač $P$ (2009) Chemical composition and nutritional value of European species of wild growing mushrooms: a review. Food Chem 113:9-16. https://doi.org/10.1016/j.foodchem.2008.07.077

20. Pleszczyńska M, Wiater A, Siwulski M, Lemieszek MK, Kunaszewska J, Kaczor J, Rzeski W, Janusz G, Szczodrak J (2016) Cultivation and utility of Piptoporus betulinus fruiting bodies as a source of anticancer agents. World J Microbiol Biotechnol 32:151. https://doi.org/10.1007/s11274-016-2114-4

21. Ferreira I, Barros L, Abreu R (2009) Antioxidants in wild mushrooms. Curr Med Chem 16:1543-1560. https://doi. org/10.2174/092986709787909587

22. Karaman M, Jovin E, Malbaša R, Matavuly M, Popović M (2010) Medicinal and edible lignicolous fungi as natural sources of antioxidative and antibacterial agents. Phyther Res 24:1473-1481. https://doi.org/10.1002/ptr.2969

23. Johnson GH, Fritsche K (2012) Effect of dietary linoleic acid on markers of inflammation in healthy persons: a systematic review of randomized controlled trials. J Acad Nutr Diet 112:1029-1041, 1041.e1-15. https://doi.org/10.1016/j.jand.2012.03.029

24. Ayaz FA, Chuang LT, Torun H, Colak A, Seslia E, Presley J, Smith BR, Glew RH (2011) Fatty acid and amino acid compositions of selected wild-edible mushrooms consumed in Turkey. Int J Food Sci Nutr 62:328-335. https://doi.org/10.3109/09637 486.2010.533160

25. Öztürk M, Duru ME, Kivrak Ş, Mercan-Doĝan N, Türkoglu A, Özler MA (2011) In vitro antioxidant, anticholinesterase and antimicrobial activity studies on three Agaricus species with fatty acid compositions and iron contents: a comparative study on the three most edible mushrooms. Food Chem Toxicol 49:1353-1360. https ://doi.org/10.1016/j.fct.2011.03.019

26. Dennis EA, Norris PC (2015) Eicosanoid storm in infection and inflammation. Nat Rev Immunol 15:511-523. https://doi. org/10.1038/nri3859

27. Gdula-Argasińska J, Czepiel J, Woźniakiewicz A, Wojtoń K, Grzywacz A, Woźniakiewicz M, Jurczyszyn A, Perucki W, Librowski T (2015) N-3 Fatty acids as resolvents of inflammation in the A549 cells. Pharmacol Rep 67:610-615. https://doi. org/10.1016/j.pharep.2015.01.001

28. Zhang Y, Mills GL, Nair MG (2003) Cyclooxygenase inhibitory and antioxidant compounds from the fruiting body of an edible mushroom, Agrocybe aegerita. Phytomedicine 10:386-390. https ://doi.org/10.1078/0944-7113-00272

29. Drori A, Shabat Y, Ben Ya'acov A, Danay O, Levanon D, Zolotarov L, Ilan Y (2016) Extracts from Lentinula edodes (Shiitake) edible mushrooms enriched with vitamin D exert an anti-inflammatory hepatoprotective effect. J Med Food 19:383-389. https:// doi.org/10.1089/jmf.2015.0111

30. Sułkowska-Ziaja K, Muszyńska B, Ekiert H (2014) Analysis of indole compounds from the fruiting bodies and the culture mycelia of Sarcodon imbricatus. Mycoscience 55:164-167. https://doi. org/10.1016/J.MYC.2013.08.001

31. Opoka W, Kała K, Krężałek R, Sułkowska-Ziaja K, Maślanka A, Muszyńska B (2017) TLC-densitometry analysis of indole compounds in mycelial culture of imleria badia and Agaricus bisporus enriched with precursors - serine or anthranilic acid. Acta Chromatogr. https://doi.org/10.1556/1326.2017.00325

32. Muszyńska B, Sułkowska-Ziaja K, Ekiert H (2013) Analysis of indole compounds in methanolic extracts from the fruiting bodies of Cantharellus cibarius (the Chanterelle) and from the mycelium of this species cultured in vitro. J Food Sci Technol 50:12331237. https://doi.org/10.1007/s13197-013-1009-8

33. Muszyńska B, Sułkowska-Ziaja K, Wójcik A (2013) Levels of physiologically active indole derivatives in the fruiting bodies of some edible mushrooms (Basidiomycota) before and after thermal processing. Mycoscience 54:321-326. https://doi.org/10.1016/j. myc.2012.11.002

34. Alhazmi H (2017) Extraction of phytochemicals betulin and betulinic acid from the chaga mushroom and their effect on MCF-7 Cells. http://knowledgecommons.lakeheadu.ca:7070/handl e/2453/4188

35. Tolstikov G, Flekhter OB, Shultz EE, Baltina LA, Tolstikov AG (2005) Betulin and its derivatives. Chemistry and biological activity. Chem Sustain Dev 13:1-29

36. Jeong JW, Lee HH, Han MH, Kim GY, Hong SH, Park C, Choi YH (2014) Ethanol extract of Poria cocos reduces the production of inflammatory mediators by suppressing the NF-kappaB signaling pathway in lipopolysaccharide-stimulated RAW 264.7 macrophages. BMC Complement Altern Med 14:101. https://doi. org/10.1186/1472-6882-14-101

37. Choi YH (2015) Induction of apoptosis by an ethanol extract of Poria cocos Wolf. in human leukemia U937 cells. Oncol Rep 34:2533-2540. https://doi.org/10.3892/or.2015.4256

38. Ma L, Chen H, Dong P, Lu X (2013) Anti-inflammatory and anticancer activities of extracts and compounds from the mushroom Inonotus obliquus. Food Chem 139:503-508. https://doi. org/10.1016/j.foodchem.2013.01.030

39. Rao YK, Fang SH, Tzeng YM (2007) Evaluation of the antiinflammatory and anti-proliferation tumoral cells activities of Antrodia camphorata, Cordyceps sinensis, and Cinnamomum osmophloeum bark extracts. J Ethnopharmacol 114:78-85. https ://doi.org/10.1016/j.jep.2007.07.028

40. Kaczor J, Klecha IM, Rzeski W, Paduch R, Zdzisińska, Barbara Pożarowski P, Kandefer-Szerszeń M (2004) Extract from Piptoporus betulinus Bull. Fr. supress human tumor cell growth. Postępy Fitoter 2:62-66

41. Tomasi S, Lohezic-Le Devehat F, Sauleau P, Bézivin C, Boustie J (2004) Cytotoxic activity of methanol extracts from Basidiomycete mushrooms on murine cancer cell lines. Pharmazie 59:290-293

42. Doskocil I, Havlik J, Verlotta R, Tauchen J, Vesela L, Macakova K, Opletal L, Kokoska L, Rada V (2016) In vitro immunomodulatory activity, cytotoxicity and chemistry of some central European polypores. Pharm Biol 54:2369-2376. https://doi. org/10.3109/13880209.2016.1156708

43. Muszyńska B, Grzywacz-Kisielewska A, Kała K, GdulaArgasińska J (2018) Anti-inflammatory properties of edible mushrooms: a review. Food Chem 243:373-381. https://doi. org/10.1016/j.foodchem.2017.09.149

44. Wangun HVK, Berg A, Hertel W, Nkengfack AE, Hertweck C (2004) Anti-inflammatory and anti-hyaluronate lyase activities of lanostanoids from Piptoporus betulinus. J Antibiot (Tokyo) $57: 755-758$

45. Gdula-Argasiska J, Grzywacz A, Krakowska A, Opoka W, Muszy-Ska B (2018) Anti-inflammatory properties of cantharellus cibarius from in vitro culture enriched in zinc. Acta Pol Pharm $75: 423-433$ 